\title{
Influence of Equatorial Dynamics on the Pacific North Equatorial Countercurrent*
}

\author{
ZUOJUN Yu \\ Joint Institute for the Study of the Atmosphere and Ocean, University of Washington, Seattle, Washington \\ JULIAN P. MCCREARY JR. \\ International Pacific Research Center, University of Hawaii at Manoa, Honolulu, Hawaii \\ WiLLIAM S. KeSSLER \\ Pacific Marine Environmental Laboratory, NOAA, Seattle, Washington \\ KATHRYN A. KELLY \\ Applied Physics Laboratory, University of Washington, Seattle, Washington
}

(Manuscript received 21 June 1999, in final form 22 February 2000)

\section{ABSTRACT}

The Pacific North Equatorial Countercurrent (NECC) is generally not well simulated in numerical models. In this study, the causes of this problem are investigated by comparing model solutions to observed NECC estimates. The ocean model is a general circulation model of intermediate complexity. Solutions are forced by climatological and interannual wind stresses, $\boldsymbol{\tau}=\left(\tau^{x}, \tau^{y}\right)$, from Florida State University and the European Centre for MediumRange Weather Forecasts. Estimates of the observed NECC structure and transport are prepared from expendable bathythermograph data and from the ocean analysis product of NOAA/National Centers for Environmental Prediction.

In solutions forced by climatological winds, the NECC develops a discontinuity in the central Pacific that is not present in the observations. The character of the error suggests that it arises from the near-equatorial $\left(5^{\circ} \mathrm{S}-\right.$ $5^{\circ} \mathrm{N}$ ) zonal wind stress, $\tau^{x}$, being relatively too strong compared to the $y$ derivative of the wind stress curl term, $(\operatorname{curl} \tau)_{y}$, associated with the intertropical convergence zone. This is confirmed in solutions forced by interannual winds, which exhibit a wide range of responses from being very similar to the observed NECC to being extremely poor, the latter occurring when near-equatorial $\tau^{x}$ is relatively too strong. Results show further that the model NECC transport is determined mainly by the strength of $(\operatorname{curl} \tau)_{y}$, but that its structure depends on near-equatorial $\tau^{x}$; thus, NECC physics involves equatorial as well as Sverdrup dynamics. Only when the two forcing features are properly prescribed do solutions develop a NECC with both realistic spatial structure and transport.

\section{Introduction}

\section{a. Observational background}

The Pacific North Equatorial Countercurrent (NECC) is a major surface current in the tropical ocean, transporting more than $20 \mathrm{~Sv}\left(\mathrm{~Sv} \equiv 10^{6} \mathrm{~m}^{3} \mathrm{~s}^{-1}\right)$ of water eastward out of the warm pool region. It is centered

\footnotetext{
* Joint Institute for the Study of the Atmosphere and Ocean Contribution Number 489, International Pacific Research Center Contribution Number 26, and Pacific Marine Environmental Laboratory Contribution Number 2160.
}

Corresponding author address: Dr. Zuojun Yu, IPRC/SOEST, University of Hawaii, 2525 Correa Road, Honolulu, HI 96822. E-mail: zuojun@soest.hawaii.edu near $5^{\circ} \mathrm{N}$ in the western Pacific and shifts poleward as it flows eastward to about $7^{\circ} \mathrm{N}$ in the central Pacific (Donguy and Meyers 1996, their Fig. 2). Its northern boundary is well defined by the adjacent westward flowing North Equatorial Current, but the location of its southern boundary is not always obvious. In the central Pacific, although it is clearly bounded near the surface by the westward South Equatorial Current (SEC), its deeper portions merge with the North Subsurface Countercurrent (NSCC; Wyrtki and Kilonsky 1984, their Fig. 2). In the western ocean, its southern edge is located as far south as $2.5^{\circ} \mathrm{N}$, and may merge with the Equatorial Undercurrent (EUC) at depth. Likewise, its bottom boundary is not clear everywhere because of the NSCC. Generally, the Pacific NECC extends only slightly below the depth of the $20^{\circ} \mathrm{C}$ isotherm $\left(Z_{20}\right)$, that is, not much deeper than $200 \mathrm{~m}$ (Wyrtki and Kilonsky 1984, their Fig. 2; G. Johnson 1999, personal communication). 
Estimates of the mean NECC transport based on expendable bathythermograph (XBT) data tend to vary considerably, partly due to uncertainties in determining the locations of its northern, southern, and bottom boundaries. Using XBT data from five frequently repeated tracks, Donguy and Meyers (1996) reported an increase of mean NECC transport toward the west, with values of $12 \mathrm{~Sv}, 14.2 \mathrm{~Sv}$, and $21 \mathrm{~Sv}$ in the eastern, central, and western Pacific, respectively. These estimates, however, are somewhat lower than those from earlier studies (e.g., Wyrtki and Kilonsky 1984; Taft and Kessler 1991), and the authors attributed this difference to selection of NECC boundaries and other factors.

\section{b. Theoretical background}

Since Sverdrup's (1947) seminal paper, the NECC is believed to be a direct response to atmospheric forcing by wind stress curl associated with the intertropical convergence zone (ITCZ). According to Sverdrup theory, the depth-integrated, zonal geostrophic current (i.e., the transport per unit latitude) is given by the full Sverdrup transport minus the Ekman transport

$$
M_{G}=\frac{1}{\beta} \int_{x}^{x_{e}}(\operatorname{curl} \tau)_{y} d x-\frac{\tau^{y}}{f},
$$

where $x$ and $y$ are eastward and northward coordinates, respectively; subscripts $x$ and $y$ indicate partial derivatives; $x_{e}$ is the location of the eastern boundary; $f$ is the Coriolis parameter, $\beta=f_{y}$; and $\tau=\left(\tau^{x}, \tau^{y}\right)$ is the annual-mean wind stress. An estimate for the NECC geostrophic transport is then given by

$$
U_{G}=\int_{y_{1}}^{y_{2}} M_{G}^{+} d y,
$$

where $M_{G}^{+}=\max \left(M_{G}, 0\right)$ is the positive part of $M_{G}$, and latitude limits are chosen as $y_{1}=2.5^{\circ} \mathrm{N}$ and $y_{2}=10^{\circ} \mathrm{N}$. As mentioned earlier, the choice of $y_{1}=2.5^{\circ} \mathrm{N}$ is reasonable for the southernmost edge of the NECC; but note that the transport value is sensitive to this choice. Since $M_{G}$ includes contributions from all eastward flows in this latitude band (the NSCC and part of the EUC, as well as the NECC), $U_{G}$ is not a precise measurement of the total NECC transport. Indeed, since the transport of the NSCC is of the order of $10 \mathrm{~Sv}$ (Johnson and McPhaden 1999), $U_{G}$ could be a considerable overestimate of the actual NECC transport.

The zonal Ekman transport in Eq. (1) is negligible (less than $2 \mathrm{~m}^{2} \mathrm{~s}^{-1}$, except for a small region east of $150^{\circ} \mathrm{W}$ and south of $5^{\circ} \mathrm{N}$ ), therefore we will focus on the contribution of $(\operatorname{curl} \tau)_{y}$ to $M_{G}$. Figure 1 plots the ( $\operatorname{curl} \tau)_{y}$ and $M_{G}$ fields for the Florida State University (FSU; top) and European Centre for Medium-Range Weather Forecasts (ECMWF; middle) climatologies described in section 2c. Because of the tilt in the $(\operatorname{curl} \tau)_{y}$ fields, $M_{G}$ tends slightly poleward as it flows eastward, consistent with the observed NECC structure. Note that the corresponding plots of FSU and ECMWF fields in Fig. 1 are very similar. Landsteiner et al. (1990), however, showed that $M_{G}$ is sensitive to different wind stress products when shorter record lengths are used (their Fig. 4 ), and concluded that more accurate winds are needed to improve ocean modeling. The total NECC transports $\left(U_{G}\right)$ based on these climatologies are plotted in the bottom panel of Fig. 1. They are also similar to each other, both increasing monotonically toward the west and attaining maximum values that approach $25 \mathrm{~Sv}$.

\section{c. Present research}

Given the success of Sverdrup theory, one might expect that it would be easy to simulate the NECC in numerical models. In fact, simulated NECCs tend to be weak (e.g., Philander et al. 1987; Grima et al. 1999) and/or poorly formed (see Fig. 9). Understanding why numerical models have this difficulty is the motivation for this research. We seek to answer the following questions: What processes determine the spatial structure and total transport of the Pacific NECC in ocean models? How sensitive are NECC simulations to forcing by different wind products? Do the deficiencies in simulated NECCs result from wind or model error? If it is wind error, can the nature of the error be characterized?

Our approach is to force an ocean model with different wind products, and to compare solutions with new estimates of observed NECC structures and transports determined from XBT and Pacific Ocean Analysis (POA) data, the latter being a data-assimilation product of model and observed thermal fields from the NOAA/ National Centers for Environmental Prediction. The ocean model used here is a $4 \frac{1}{2}$-layer system with active thermodynamics and mixed layer physics, essentially a general circulation model of intermediate complexity. Solutions are forced by climatological and interannual versions of FSU and ECMWF winds.

Our results support the idea that wind inaccuracies cause poor NECC simulation, and identify the problematic aspects of the wind fields and the ocean response. One of our main results is that when solutions fail to develop a realistic NECC structure, they do so in a distinct manner by developing a discontinuity in the central ocean. This failure is traceable to wind inaccuracies in two specific regions: $(\operatorname{curl} \tau)_{y}$ in the ITCZ region and $\tau^{x}$ in the near-equatorial region. Only when the forcing in these two regions is properly prescribed do solutions develop a NECC with both realistic spatial structure and transport.

\section{Methodology}

We begin this section by describing how observed NECC structures and transports are estimated from the $\mathrm{XBT}$ and POA data (section 2a). Then, we review the ocean model briefly (section $2 \mathrm{~b}$ ) and comment on the wind products used to force the model (section 2c). 

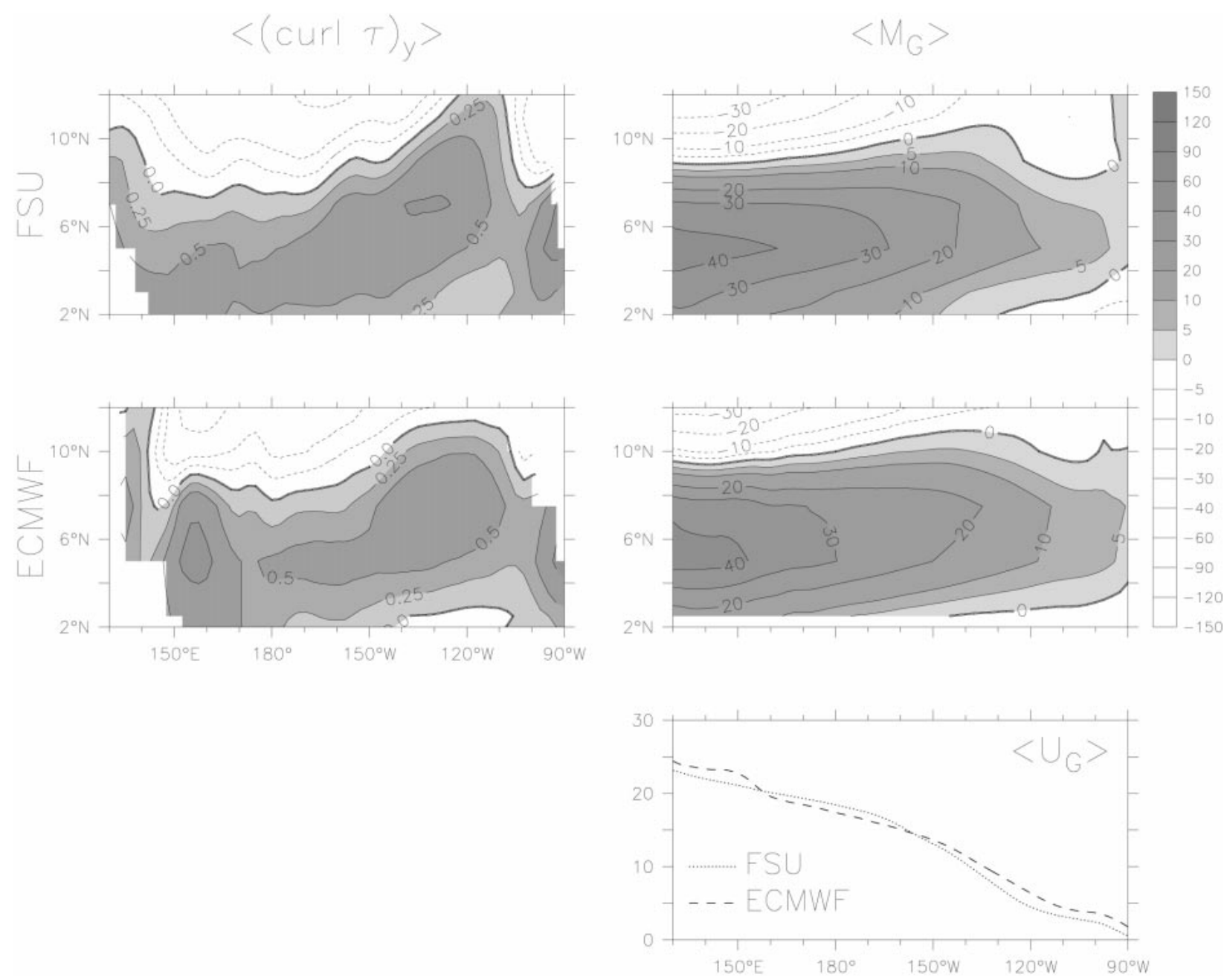

FIG. 1. Mean $(\operatorname{curl} \tau)_{y}$ and $M_{G}$ fields from the FSU and ECMWF climatologies in the top and middle panels, respectively. The $U_{G}$ curves from FSU (dotted curve) and ECMWF (dashed curve) climatologies are shown in the bottom panel. The contour interval for (curl $\tau$ ), is 0.5 $\times 10^{-13} \mathrm{~N} \mathrm{~m}^{-4}$, with the additional contours for $\pm 0.25 \times 10^{-13} \mathrm{~N} \mathrm{~m}^{-4}$; contour intervals for $M_{G}\left(\mathrm{~m}^{2} \mathrm{~s}^{-1}\right)$ are indicated along the right edge of the plot. The units for $U_{G}$ are Sverdrups. Angle brackets indicate a time average. Eastward (positive) values of $M_{G}$ are shaded.

\section{a. Ocean observations}

Climatological, zonal geostrophic currents were determined from the tropical Pacific XBT profiles (Kessler 1990 ) as follows. First, the average annual cycle of temperature for the period 1970-1987 was constructed from the approximately 175000 irregularly spaced profiles, by interpolating and averaging them onto a regular grid with a resolution of $\Delta x=5^{\circ}, \Delta y=2^{\circ}, \Delta z=10 \mathrm{~m}$, and $\Delta t=1$ month. The depth of $Z_{20}$ was then determined from the gridded temperatures, and the zonal geostrophic current $u_{\mathrm{ob}}$ was estimated from $Z_{20}$ by

$$
u_{\mathrm{ob}}=-\frac{g}{f} \frac{\Delta \rho}{\rho} \frac{\partial Z_{20}}{\partial y},
$$

that is, by assuming that $Z_{20}$ defines the interface at the bottom of a reduced-gravity system. The depth-integrated current above $Z_{20}$ is

$$
M_{\mathrm{ob}}=u_{\mathrm{ob}} Z_{20},
$$

and the total NECC transport is

$$
U_{\mathrm{ob}}=\int_{y_{1}}^{y_{2}} M_{\mathrm{ob}}^{+} d y,
$$

where $M_{\mathrm{ob}}^{+}=\max \left(M_{\mathrm{ob}}, 0\right)$, and $y_{1}$ and $y_{2}$ are defined as in Eq. (2). Equation (3) requires choosing a value for the parameter $\Delta \rho / \rho$. By matching the transports derived from (5) with geostrophic transports found from the full vertical resolution above $Z_{20}$, Kessler and Taft (1987) found that a value of $\Delta \rho / \rho=4 \times 10^{-3}$ best fit the data, and we therefore use that value here.

Note that these definitions for $M_{\mathrm{ob}}$ and $U_{\mathrm{ob}}$ only include transports above $Z_{20}$, and so differ from the corresponding Sverdrup fields $M_{G}$ and $U_{G}$, which include deeper eastward flows (e.g., the NSCC). The value of 

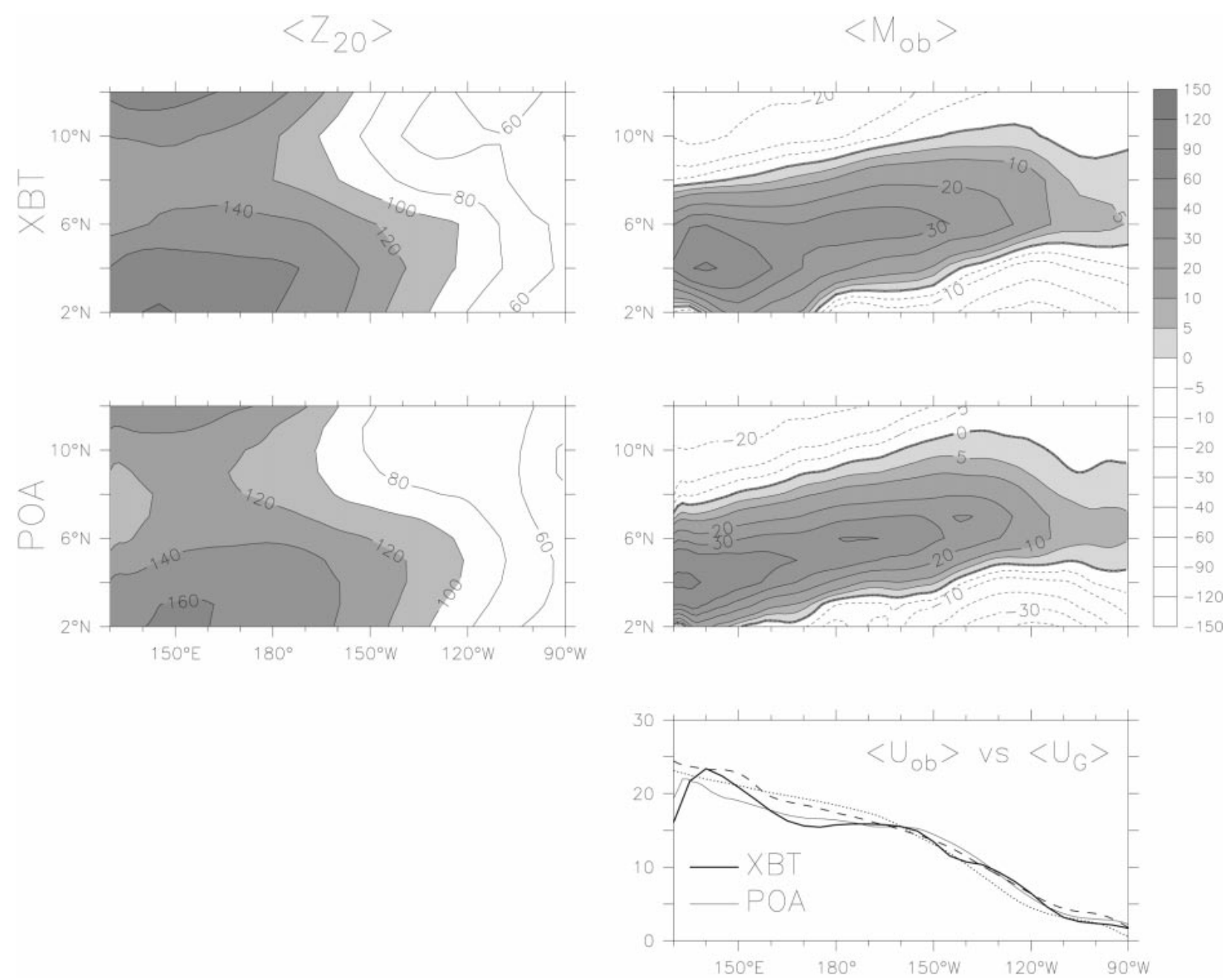

FIG. 2. Mean $Z_{20}$ and $M_{\mathrm{ob}}$ fields from the XBT and POA data in the top and middle panels, respectively. The bottom panel shows $U_{\mathrm{ob}}$ from the XBT (thick curve) and POA (thin curve) data; it also includes $U_{G}$ curves from the bottom panel of Fig. 1 . The contour interval is $20 \mathrm{~m}$ for $Z_{20}$; contour intervals for $M_{\mathrm{ob}}\left(\mathrm{m}^{2} \mathrm{~s}^{-1}\right)$ are indicated along the right edge of the plot. The units for $U_{\mathrm{ob}}$ are Sverdrups.

$U_{\text {ob }}$ should also be smaller than some of the earlier XBT estimates that included part of the NSCC.

The POA dataset consists of monthly mean estimates of the state of the tropical Pacific starting in 1980, and therefore provides information on interannual variability, as well as climatological mean. This dataset is not based entirely on observations, but rather is model output in which surface and subsurface temperature observations, including much of the XBT data, have been assimilated (Behringer et al. 1998). The assimilation improves the model's subsurface thermal structure considerably (e.g., Ji and Smith 1995; also compare Figs. 3 and 9 below), and its climatological mean is very similar to the one obtained from the XBT data (section 3a).

To be consistent with estimates using the XBT data, NECC transports are also determined from POA's $Z_{20}$ field, using eqs.(3)-(5) and the same choice of the value for $\Delta \rho / \rho$. We chose the period 1980-1996 to obtain a
POA climatology because of the record length of the XBT data, but the climatology is not much changed if the POA data from 1997 (a strong El Niño year) is included. Finally, the POA data were also smoothed in $x$ with a 5-point boxcar filter since the POA data have a finer zonal resolution $\left(\Delta x=1.5^{\circ}\right)$ than the XBT data.

\section{b. Ocean model}

The ocean model consists of four active layers with variables of thicknesses $h_{i}$, velocities $\mathbf{v}_{i}$, salinities $S_{i}$, and temperatures $T_{i}$ (layer index $i=1,2,3$, or 4), overlying a deep, inert ocean where the pressure gradient vanishes (a 41/2-layer system). Each of the layers represents water generated primarily by a specific process, and hence corresponds mostly to a single watermass type: Layer 1 is the surface mixed layer, determined by Kraus-Turner (1967) physics; layer 2 is the seasonal thermocline; layers 3 and 4 represent ther- 


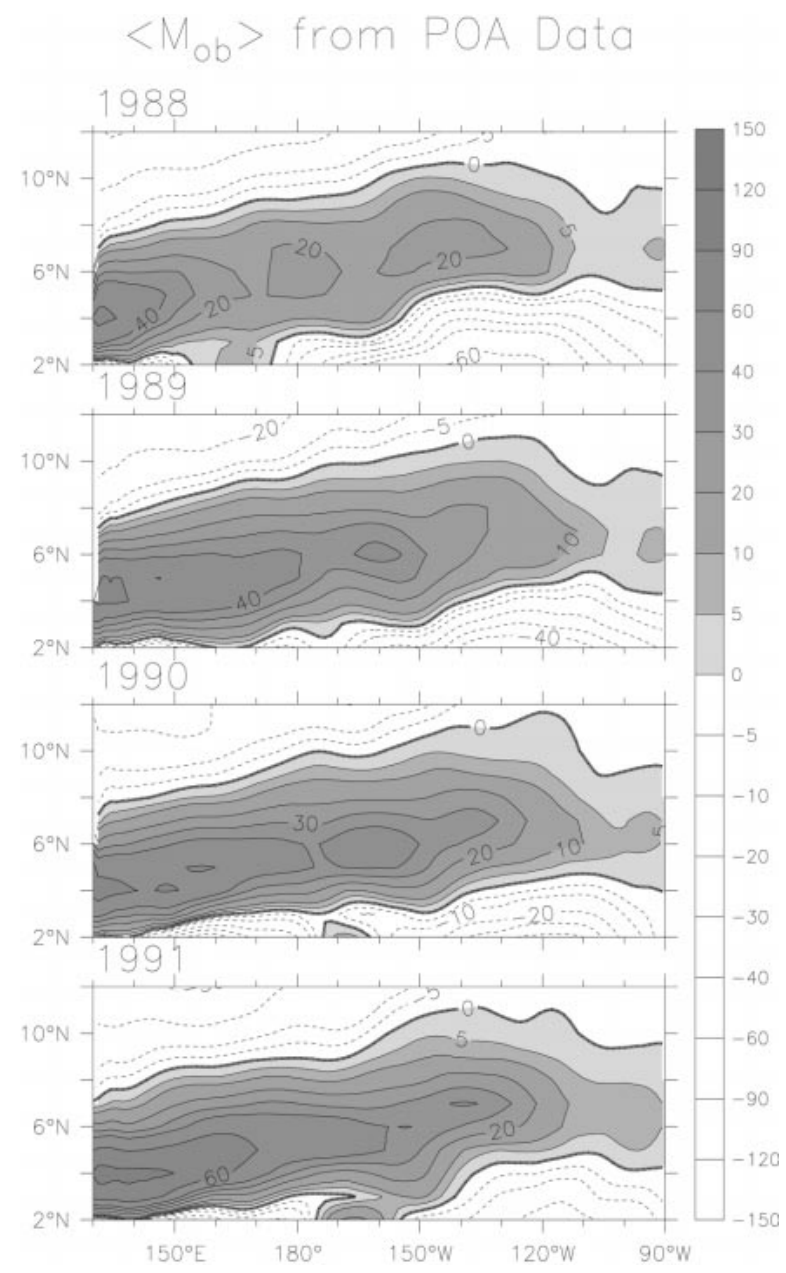

FIG. 3. Annual-mean transport per unit latitude $M_{\mathrm{ob}}$ of 1988-91 from the POA data forced by mean Hellerman and Rosenstein (1983) winds plus anomalies from the FSU monthly mean winds with $C_{D}=$ $1.3 \times 10^{-3}$ and with data assimilation. Contour intervals are indicated along the right edge of the plot. The unit is $\mathrm{m}^{2} \mathrm{~s}^{-1}$.

mocline and upper-intermediate waters, respectively. To simulate the processes of upwelling, subduction, and diapycnal mixing, fluid is allowed to transfer across the interfaces between adjacent layers. When this occurs, mass, heat and salt remain conserved. It can be regarded as an extension of the Lu et al. (1998) 31/2-layer model, modified to include a seasonal-thermocline layer and the active thermodynamics described in Han et al. (1999).

Because the model is thermodynamically active, surface boundary conditions include forcing by heat and freshwater fluxes, as well as wind stress (section 2c). For climatological solutions, monthly mean shortwave radiation, longwave radiation, precipitation, air temperature, and specific humidity from the da Silva et al. (1994) dataset are used to calculate the heat and buoyancy fluxes along with model $T_{1}$. For interannual solutions, the Seager and Blumenthal (1994) approach is used to determine air temperature and humidity.
The model basin is an idealized representation of the tropical Pacific Ocean from $30^{\circ} \mathrm{S}$ to $30^{\circ} \mathrm{N}$. The northern and southern boundaries are closed (to ensure that the system conserves mass), and $S_{1}$ and $T_{1}$ are relaxed back to the Levitus (1982) monthly mean climatology from $30^{\circ}$ to $20^{\circ}$ (tapering off linearly from $25^{\circ}$ to $20^{\circ}$ ) with a timescale of one month. The grid resolution is $\Delta x=$ $1^{\circ}$ and $\Delta y=0.5^{\circ}$, and the integration time step is usually 1 hour.

When forced by climatological winds, the model is spun up from a state of rest for 4 years and year 5 is used for analysis. For interannual winds, the fourth year of the FSU climatology run is used as the initial state, and interannual winds are introduced gradually over a period of 15 days.

For comparison with the XBT and PAO results based on $Z_{20}$, we use the depth-integrated, zonal geostrophic current over layers 1 and 2 ,

$$
M_{\mathrm{mo}}=h_{1} u_{1}+h_{2} u_{2}-\tau^{y} / f,
$$

and the associated NECC geostrophic transport,

$$
U_{\mathrm{mo}}=\int_{y_{1}}^{y_{2}} M_{\mathrm{mo}}^{+} d y,
$$

where $M_{\mathrm{mo}}^{+}=\max \left(M_{\mathrm{mo}}, 0\right)$, and $y_{1}$ and $y_{2}$ are defined as in Eq. (2). These definitions essentially assume that the model's $Z_{20}$ field is $Z_{\mathrm{mo}}=h_{1}+h_{2}$. (A more precise definition might be $Z_{\mathrm{mo}}=h_{1}+h_{2}+\alpha h_{3}$, with $\alpha=$ 0.5 say, which fits better with layer 3 being the thermocline layer and $Z_{20}$ being roughly the midthermocline depth. This choice, however, does not increase $M_{\text {mo }}$ much because almost all of the model NECC is confined within layers 1 and 2.) Finally, the model output is smoothed in $x$ with a 7-point boxcar filter for comparison with observations.

\section{c. Winds}

Two gridded wind products are used to force the model: FSU monthly mean pseudostresses for the period of 1961-1996, and ECMWF monthly mean wind stresses for 1985-96. Unless specified otherwise, the FSU wind stress is estimated from its pseudostress assuming an air density $\rho_{a}=1.2 \mathrm{~kg} \mathrm{~m}^{-3}$ and a drag coefficient $C_{D}=$ $1.3 \times 10^{-3}$. The ECMWF monthly mean wind stresses are based on its 12-hourly operational wind product at 10-m height, with $C_{D}$ calculated according to the Large and Pond (1981) algorithm. Climatological monthly mean wind stresses are formed from both datasets using the entire records mentioned above.

During this study, we also considered other wind products. For example, the solution forced by Hellerman and Rosenstein (1983) winds was similar to that forced by FSU climatology. For interannual winds, we experimented with the European Radar Sensor (ERS) winds, which gives similar results as ECMWF winds for the period during which ERS data was available. 

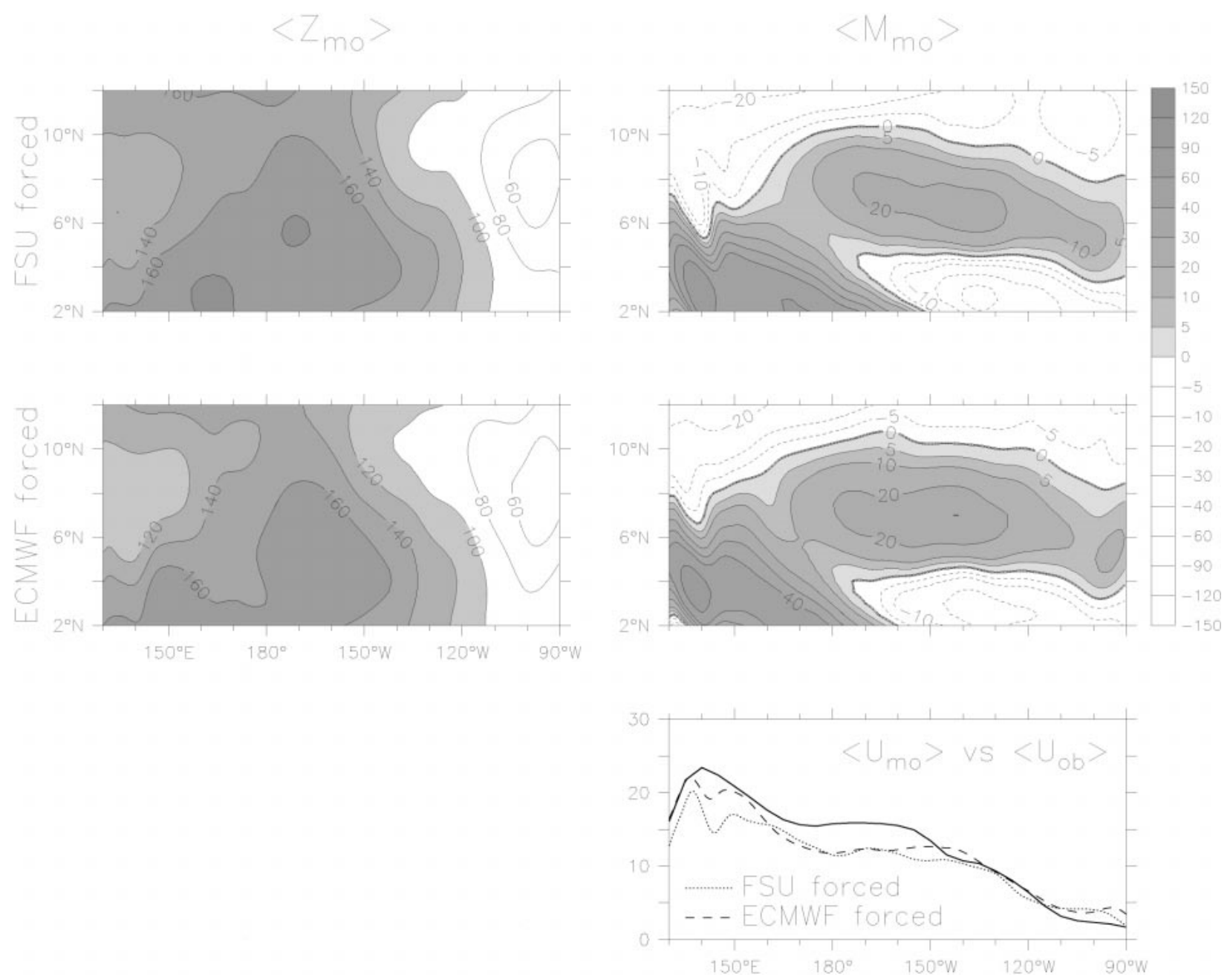

FIG. 4. Similar to Fig. 2, except for the model solutions forced by FSU and ECMWF climatologies in the top and middle panels, respectively. The bottom panel shows $U_{\text {mo }}$ forced by the FSU (dotted curve) and ECMWF (dashed curve) climatologies, as well as $U_{\mathrm{ob}}$ from the XBT data (thick curve). The striking difference between Fig. 4 and Fig. 2 is the discontinuity in the spatial structure of the model NECC near the date line.

\section{Results}

In section $3 \mathrm{a}$, we describe the NECC structure and transport determined from the XBT and POA data, $M_{\mathrm{ob}}$ and $U_{\mathrm{ob}}$, and compare them with the corresponding Sverdrup fields, $M_{G}$ and $U_{G}$. Then, $M_{\mathrm{mo}}$ and $U_{\mathrm{mo}}$ fields from the climatological (section $3 b$ ) and interannual (section 3c) solutions are discussed, and compared with their observed and Sverdrup counterparts. The comparisons reveal discrepancies between the modeled and observed NECC that are traceable to wind inaccuracies in specific regions.

\section{a. Observed NECC}

The structure of the mean NECC determined from the XBT data is shown in the top panels of Fig. 2. The $Z_{20}$ field shoals from west to east and has a well-defined ridge $\left(7^{\circ}-10^{\circ} \mathrm{N}\right)$ and trough $\left(2^{\circ}-5^{\circ} \mathrm{N}\right)$ structure. The $M_{\mathrm{ob}}$ field shows a NECC between the ridge and trough that shifts poleward from about $4^{\circ} \mathrm{N}$ in the far west to $7^{\circ} \mathrm{N}$ in the east. There is a strong westward flow south of the NECC, the northern branch of the SEC. The total NECC transport $U_{\mathrm{ob}}$ (thick curve in the bottom panel) shows a gradual increase toward the west, with a maximum of $23 \mathrm{~Sv}$ near $140^{\circ} \mathrm{E}$.

The $Z_{20}$ and $M_{\mathrm{ob}}$ fields determined from the POA data for the 1980-96 period (middle panels of Fig. 2) are very similar to the XBT fields. The most obvious difference is that the ridge in the $Z_{20}$ field is somewhat broader in the east in the POA data. The SEC also reaches farther west along $2^{\circ} \mathrm{N}$ and the northern boundary of the NECC seems to tilt more in the POA fields. The total NECC transport $U_{\mathrm{ob}}$ determined from the POA data (thin curve in the bottom panel) also agrees with the XBT estimate (thick curve).

There are intriguing similarities and differences be- 

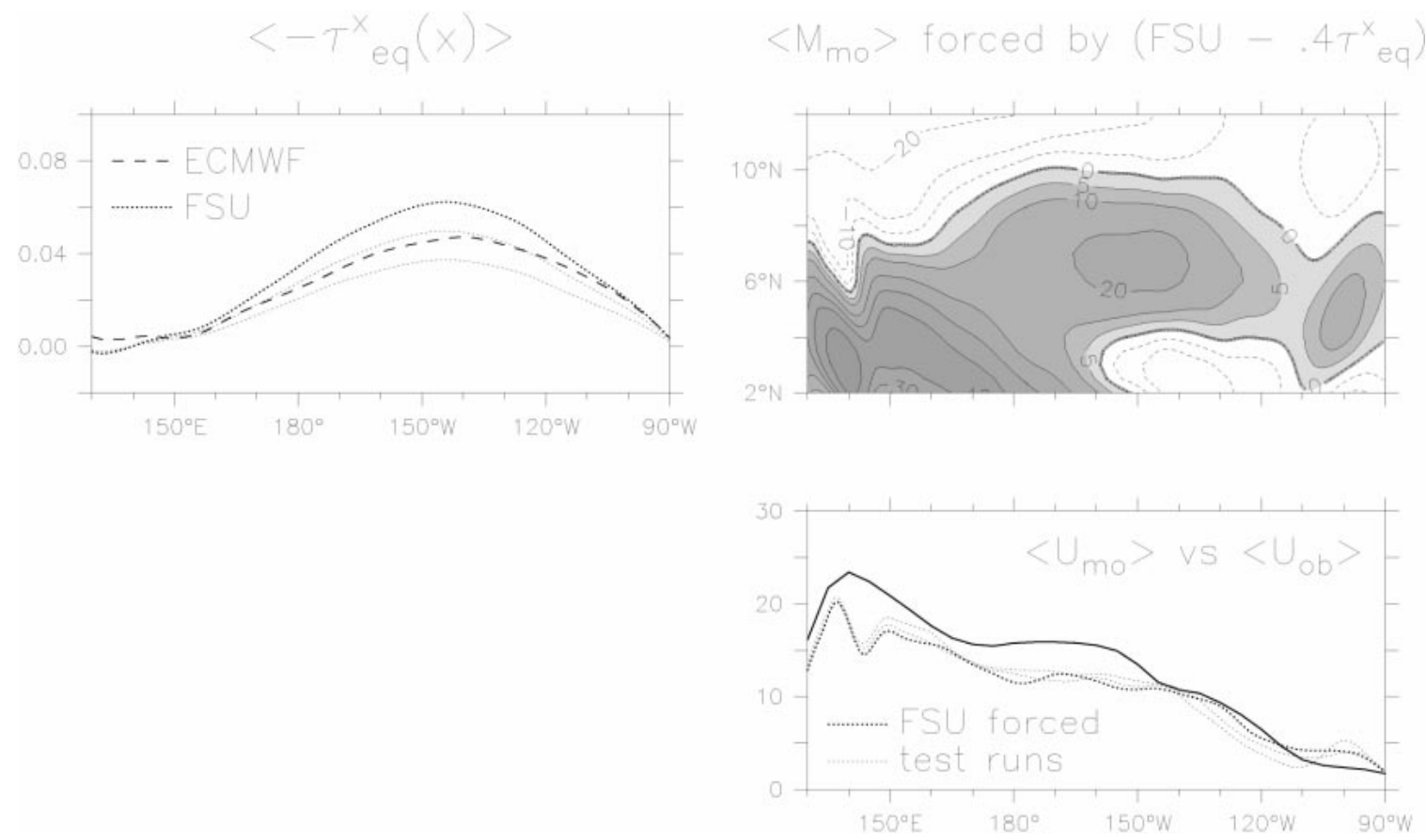

FIG. 5. The top-left panel shows the structures of $-\tau_{\mathrm{eq}}^{x}(x)$ obtained from FSU (heavy-dotted) and ECMWF (dashed) climatologies, as well as those for $0.8 \tau_{\mathrm{eq}}^{x}(x)$ and $0.6 \tau_{\mathrm{eq}}^{x}(x)$ for the FSU winds (light-dotted curves), where $\tau_{\mathrm{eq}}^{x}(x)$ is defined in Eq. (8). The topright panel is $M_{\text {mo }}$ when $40 \%$ of $\tau_{\text {eq }}^{x}(x)$ is removed from the FSU climatology at each latitude; it should be compared with the top-right panel of Fig. 4 (both having the same shading and contour intervals) to see the impact of near-equatorial $\tau^{x}$ on NECC structures. The bottom panel shows $U_{\text {mo }}$ from solutions forced by the FSU (heavy-dotted curve) and modified FSU (light-dotted curves) climatologies, as well as $U_{\mathrm{ob}}$ from the XBT data (thick curve). The units for $\tau_{\mathrm{eq}}^{x}, M_{\mathrm{mo}}$, and $U_{\mathrm{ob}}$ are $\mathrm{N} \mathrm{m}^{-2}, \mathrm{~m}^{2} \mathrm{~s}^{-1}$, and Sverdrups, respectively.

tween the $M_{\mathrm{ob}}$ and $M_{G}$ fields. Sufficiently far from the equator $\left(y \geq 4^{\circ} \mathrm{N}\right)$ and away from the western boundary, their structures are much the same. Near the equator, however, $M_{\mathrm{ob}}$ and $M_{G}$ differ markedly in that the SEC establishes a well-defined southern boundary in $M_{\mathrm{ob}}$ (Fig. 2) but not in $M_{G}$ (Fig. 1). This difference is understandable since the SEC is forced by near-equatorial $\tau^{x}$ and is significantly influenced by momentum advection (Philander and Pacanowski 1980; McCreary 1985), and hence cannot be fully described by Sverdrup theory. This is one indication of the influence of equatorial dynamics on the NECC structure.

Note that both $U_{\mathrm{ob}}$ curves are similar to the $U_{G}$ curves (bottom panel of Fig. 2). This agreement would seem to indicate a consistency between observation and theory, but, as noted in section $1 \mathrm{~b}, U_{G}$ includes a contribution from the NSCC that is not included in the definition of $U_{\mathrm{ob}}$, so it should be larger than $U_{\mathrm{ob}}$. The fact that it is not larger is an indication that the wind products used to obtain the $U_{G}$ curves are in error, specifically that their regions of positive $(\operatorname{curl} \tau)_{y}$ are too weak.

The good comparison between mean XBT and POA results gives us some confidence that the POA data may be used to show observed interannual variability of the NECC. Figure 3 shows $M_{\mathrm{ob}}$ fields determined from annual-mean POA data each year from 1988 to 1991. Although the annual-mean NECCs from different years have similar spatial patterns, they differ in magnitude and also near the NECC southern boundary, where equatorial dynamics are expected to become important.

\section{b. Climatological NECC in the model}

Figure 4 shows the spatial structures of the model NECCs forced by FSU (top panels) and ECMWF (middle panels) climatological winds. The overall structures of the $Z_{\mathrm{mo}}$ fields are similar to those for $Z_{20}$ in Fig. 2, except that the ridges forming the northern boundary of the NECC at $7^{\circ}-10^{\circ} \mathrm{N}$ are not as well defined in $Z_{\mathrm{mo}}$. In contrast, $M_{\mathrm{mo}}$ fields differ strikingly from $M_{\mathrm{ob}}$, with the model NECC (nearly) developing a discontinuity near the date line. The discontinuity seems to be related to the westward flowing SEC farther to the east, and is slightly worse in solutions forced by FSU winds than by ECMWF winds. The bottom panel of Fig. 4 shows the corresponding $U_{\mathrm{mo}}$ curves from the climatological experiments; they are quite similar east of $150^{\circ} \mathrm{E}$. In general, however, $U_{\text {mo }}$ is about $5 \mathrm{~Sv}$ smaller than $U_{\mathrm{ob}}$ in the central Pacific.

The poorly formed ridges in $Z_{\mathrm{mo}}$ and weak transports of $U_{\text {mo }}$ indicates that the wind stress curl is weak in both climatologies, whereas the discontinuity, apparently linked to the SEC to its east, suggests that near-equatorial $\tau^{x}$ is too strong. To investigate the latter possi- 

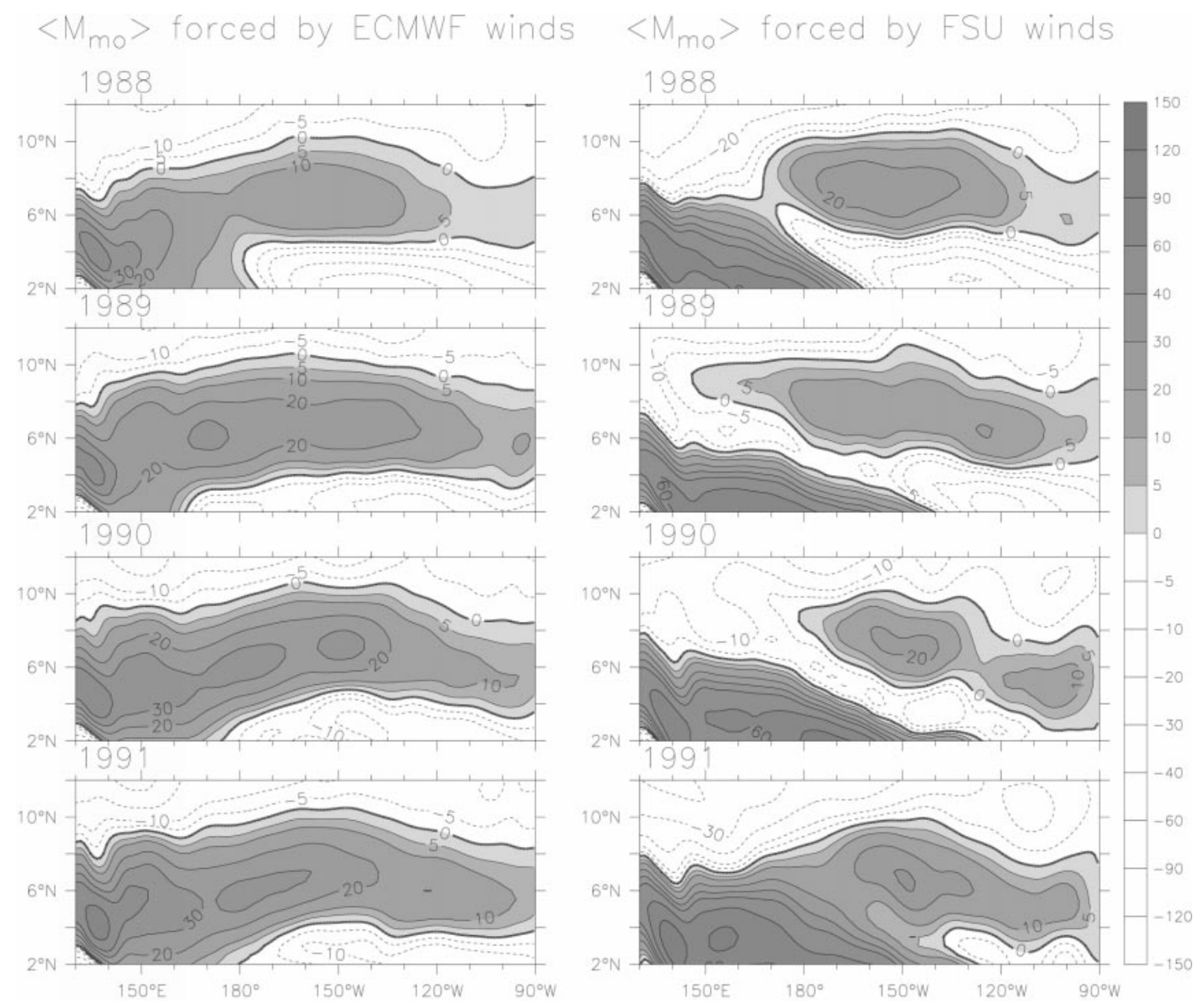

FIG. 6. Similar to Fig. 3, except for $M_{\mathrm{mo}}$ forced by ECMWF and FSU monthly mean wind stresses in the left and right panels, respectively. In contrast to the ECMWF solutions, the FSU solution lacks consistency and has poor NECC structures.

bility, we first compared the near-equatorial $\tau^{x}$ fields from the two climatologies, defining an equatorial-band average $\tau^{x}$

$$
\tau_{\mathrm{eq}}^{x}(x)=\frac{1}{L_{y}} \int_{5^{\circ} \mathrm{S}}^{5^{\circ} \mathrm{N}} \tau^{x}(x, y) d y,
$$

where $L_{y}=10^{\circ}$. The top-left panel of Fig. 5 shows that $\tau_{\mathrm{eq}}^{x}(x)$ from the FSU climatology (heavy-dotted curve) is about 20\% larger than that for ECMWF (dashed curve), consistent with the fact that the discontinuity is somewhat worse in the FSU forced solution. Then, we removed a fraction of the near-equatorial winds from the FSU climatology by subtracting $\gamma \tau_{\mathrm{eq}}^{x}(x)$ from $\tau^{x}$ at each latitude, where $0<\gamma<1$. Since $\tau_{\mathrm{eq}}^{x}(x)$ is independent of $y$, this modification of the forcing does not affect the $(\operatorname{curl} \tau)_{y}$ field that is the Sverdrup part of the flow. In a test run using the FSU climatological winds with $\gamma=0.2$, the discontinuity became less as the SEC weakens; the solution is much improved when $\gamma$ is increased to 0.4 (top-right panel of Fig. 5). This improvement suggests that $\tau_{\mathrm{eq}}^{x}(x)$ is too strong in the climatol- ogies, but does not rule out the possibility that the $(\operatorname{curl} \boldsymbol{\tau})_{y}$ field is too weak.

It is worth noting that the magnitude of the total NECC transport $U_{\text {mo }}$ did not seem to be affected by $\tau_{\mathrm{eq}}^{x}(x)$ : As a fraction of $\tau_{\mathrm{eq}}^{x}(x)$ was removed from the forcing field, $U_{\mathrm{mo}}$ remained much the same (bottom panel of Fig. 5). This implies that the model NECC transport mainly depends on the strength of the ( $\operatorname{curl} \tau)_{y}$ field, consistent with Sverdrup theory.

\section{c. Interannual NECC in the model}

Two experiments were carried out, in which the model was forced by ECMWF and FSU monthly mean winds for the period of 1985-96. These solutions provide evidence that wind error, rather than model error, is the main cause of the discontinuity in the spatial structure of the model NECC.

Figure 6 shows the annual-mean transport per unit latitude fields of $M_{\mathrm{mo}}$ from both solutions for the years of 1988-91, which is to be compared to the observed 
$\left\langle U_{G}\right\rangle v S\left\langle U_{o b}\right\rangle$

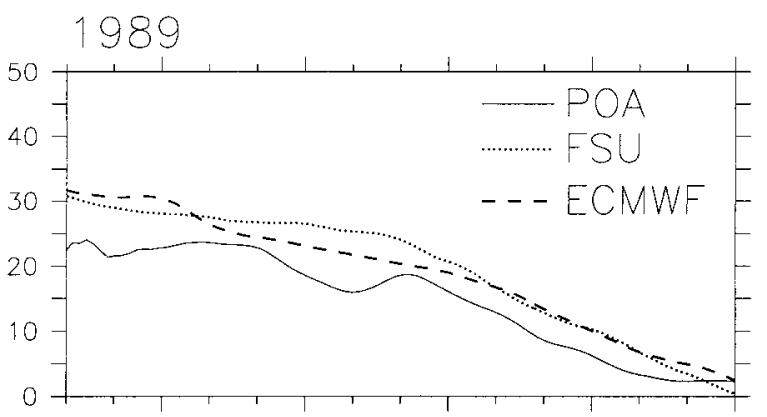

1991

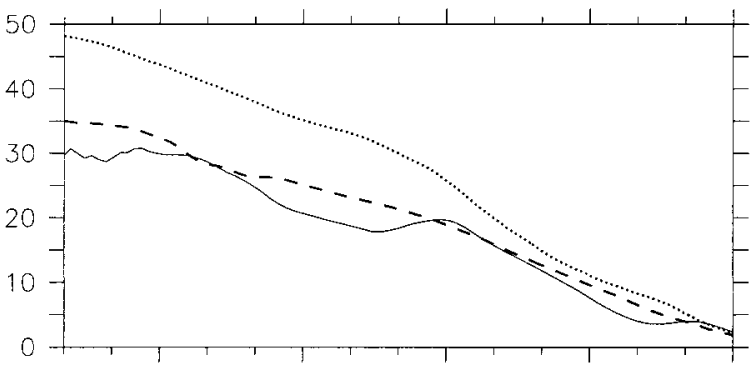

1993

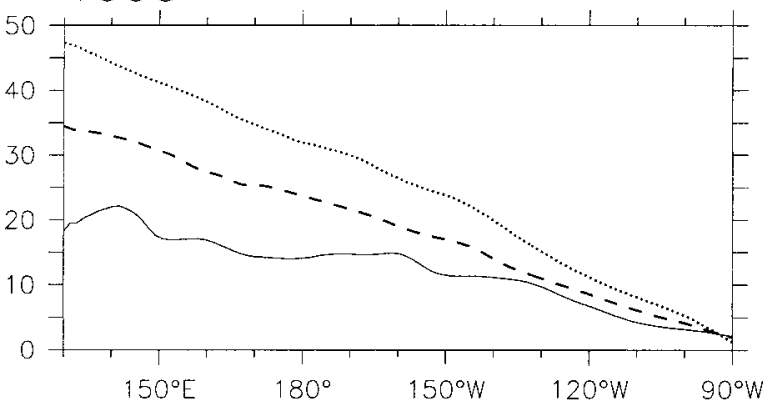

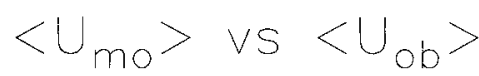
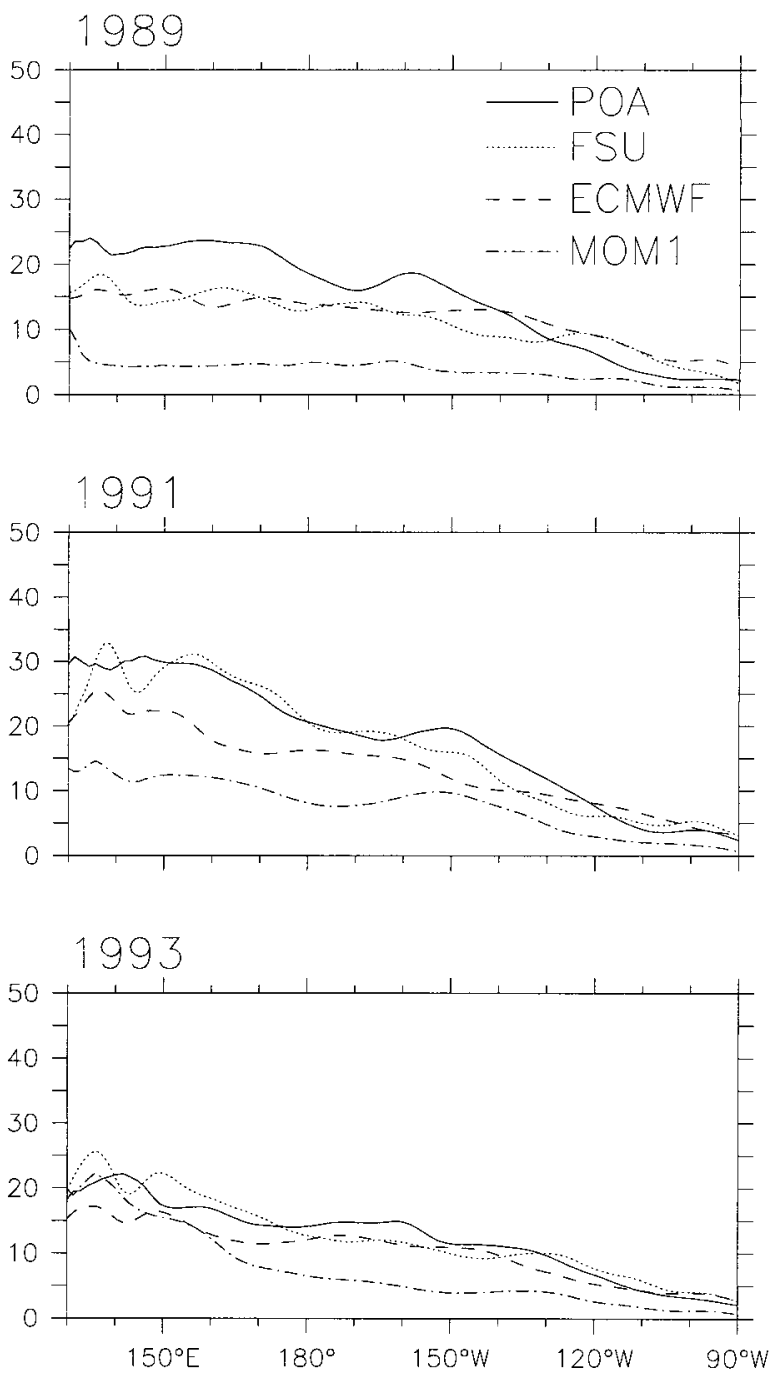

FIG. 7. Left panels: Annual-mean total NECC transport $U_{G}$ from ECMWF (dashed) and FSU (dotted) winds, along with annual-mean $U_{\mathrm{ob}}$ from the POA data (solid curves). Right panels: Annual-mean $U_{\text {mo }}$ forced by ECMWF (dashed) and FSU (dotted) winds, again with annualmean $U_{\mathrm{ob}}$ for the POA data (solid curves) in the right panels. The dash-dotted curves in the right panels are the total NECC transport from the MOM1 solution shown in Fig. 9 and discussed in section 3d. The units are Sverdrups.

estimates in Fig. 3. The model NECC forced by ECMWF winds is poorly simulated before 1988 (not shown) because $(\operatorname{curl} \tau)$, was very weak; it still shows a trace of discontinuity near the date line in 1988 (topleft panel). The solution compares well with observations for the remaining years, except that the magnitudes were somewhat weaker. In contrast, the discontinuity remains in the solution forced by FSU winds (right panels). The responses of both solutions for the subsequent 1992-96 period are similar in pattern to those of 1991 (bottom panels).

In contrast to the large spatial differences that exist between the two $M_{\text {mo }}$ fields, the total NECC transport curves $U_{\mathrm{mo}}$ forced by these two wind products can sometimes be very similar because $U_{\text {mo }}$ is a meridional in- tegration of $M_{\mathrm{mo}}$. One such example is shown in the top panels of Fig. 7: The $U_{\mathrm{mo}}$ curves of 1989 have similar magnitudes for ECMWF and FSU forced solutions (dashed and dotted curves in top-right panel, respectively), as do their $U_{G}$ curves (top-left panel). Both $U_{\text {mo }}$ curves of 1989, however, are smaller than $U_{\text {ob }}$ estimated from the POA data for the same period (solid curve in the top-right panel). The annual-mean $U_{\text {mo }}$ becomes much closer to $U_{\text {ob }}$ during 1991 in the FSU solution (dotted and solid curves in the middle-right panel), and by 1993 the annual-mean $U_{\text {mo }}$ in the ECMWF solution is also close to $U_{\mathrm{ob}}$ (dashed and solid curves in the bottom-right panel). Note that the improvement in $U_{\text {mo }}$ fields from 1989-93 corresponds to increases in $U_{G}$ fields shown in the left panels, suggesting that it resulted 

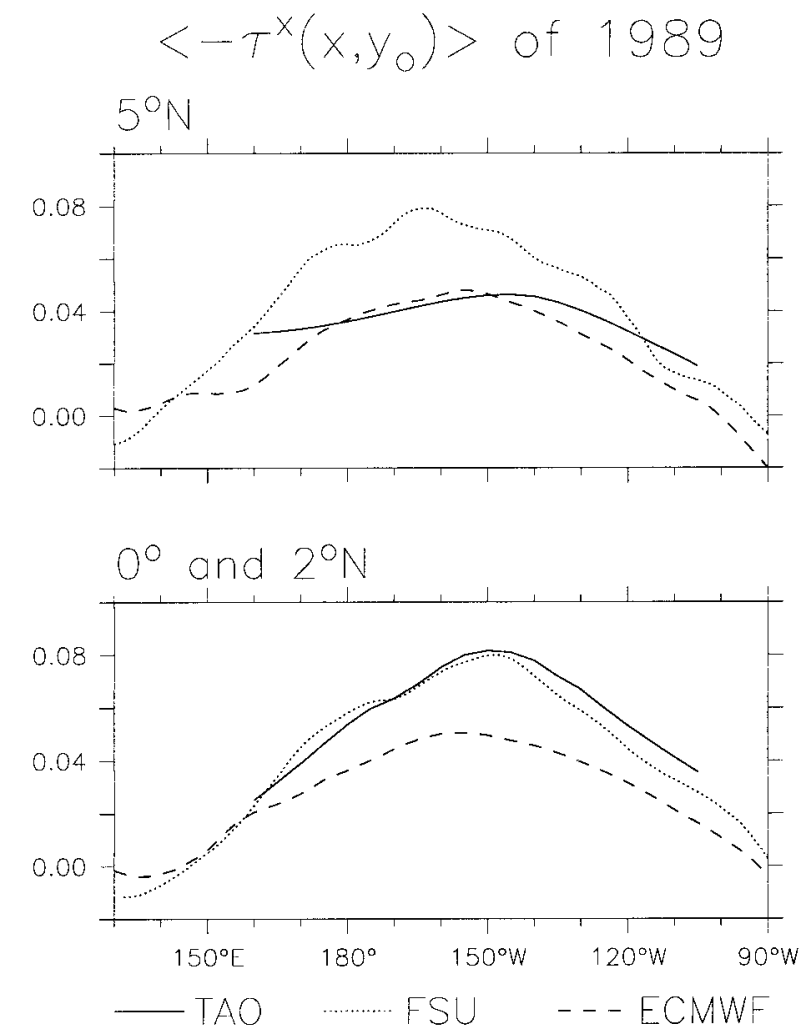

FIG. 8. Annual-mean $-\tau^{x}$ during 1989 at $0^{\circ}-2^{\circ} \mathrm{N}$ and $5^{\circ} \mathrm{N}$ for TAO (solid), ECMWF (dashed), and FSU (dotted) data. The reduction of $\tau^{x}$ in TAO data from $2^{\circ} \mathrm{N}$ to $5^{\circ} \mathrm{N}$, which is indicative of the location and strength of the ITCZ, is missing from both ECMWF and FSU wind products. Units are $\mathrm{N} \mathrm{m}^{-2}$.

from improved $(\operatorname{curl} \tau)_{y}$ fields due to either better wind observations and/or better assimilation techniques.

The improvement of $U_{\mathrm{mo}}$ towards $U_{\mathrm{ob}}$ during early 1990 s is encouraging. However, a good comparison of $U_{\text {mo }}$ and $U_{\text {ob }}$ does not necessary guarantee a realistic spatial structure for the model NECC. For example, the $U_{\text {mo }}$ curve of 1991 from the FSU solution compares well with $U_{\text {ob }}$ (middle-right panel of Fig. 7), but its NECC spatial structure remains poor (bottom-right panel of Fig. 6). This is an indication that the simulation of NECC structure involves more than Sverdrup dynamics.

The fact that our model is able to produce a realistic NECC structure after 1988 when forced by ECMWF monthly mean winds suggests that some error in the FSU winds is likely responsible for its poor simulation. To illustrate why the model NECCs have such different spatial structures when forced by the two wind products, we consider the year 1989: The $U_{G}$ curves are very similar for the two wind products during this year (topleft panel of Fig. 7), but their $M_{\text {mo }}$ fields are strikingly different (upper-middle panels of Fig. 6). We then compare these wind products with in situ data from the Tropical Atmosphere Ocean (TAO) Array (McPhaden 1993) for the same period. (The TAO wind stresses were

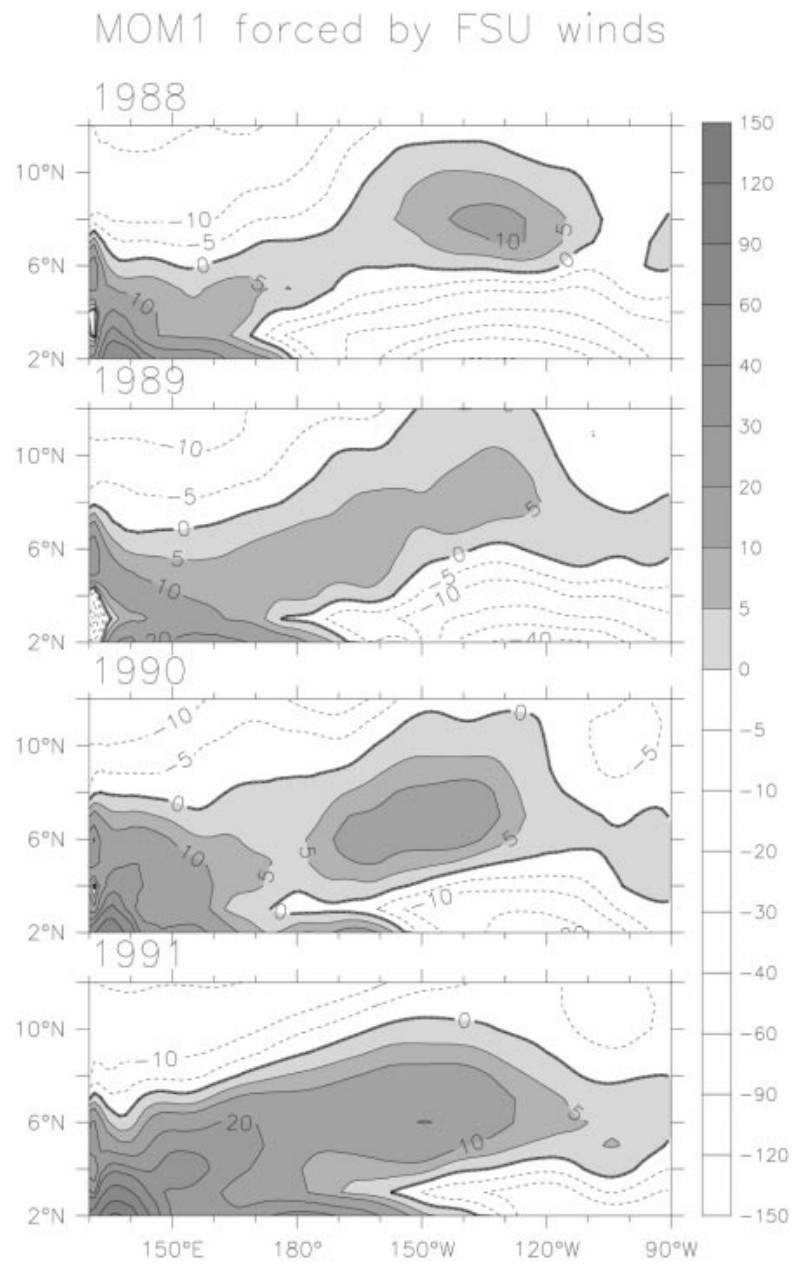

FIG. 9. Annual-mean transport per unit latitude from MOM1 forced by the same wind stresses as those used to produce Fig. 3, except without data assimilation.

determined from buoy winds adjusted to 10-m height and the same $\rho_{a}$ and $C_{D}$ as for the FSU data.)

Figure 8 shows that $\tau^{x}$ from the FSU data is similar to that from TAO near the equator (bottom panel), but is much larger than TAO at $5^{\circ} \mathrm{N}$ (bottom panel). The significant reduction of $\tau^{x}$ from the equator to $5^{\circ} \mathrm{N}$ in the TAO data indicates the location and strength of the ITCZ, but this feature is missing in the FSU winds. This difference suggests that the failure of the FSU solution was due to a weak ITCZ. The ECMWF winds also show a weak ITCZ, as indicated by the small change of $\tau^{x}$ from the equator (bottom panel) to $5^{\circ} \mathrm{N}$ (top panel). However, the ECMWF winds are much weaker than the TAO winds near the equator. The fact that the ECMWF solution has a realistic spatial structure must then result from its near-equatorial $\tau^{x}$ being much weaker than that of the TAO and FSU winds. In other words, for the ECMWF winds weak ( $\operatorname{curl} \tau)_{y}$ in the region of the ITCZ is matched by weak $\tau^{x}$ in the near-equatorial region. Consistent with the relatively weak ITCZ indicated by 
Fig. 8, the total NECC transport $U_{\text {mo }}$ of 1989 is rather small for both ECMWF and FSU solutions (top-right panel of Fig. 7).

It is worth noting that the TAO buoy winds go into both FSU and ECMWF analyses; particularly beginning about 1991, they become a significant constraint on those analyses. Hence, it is curious that the analyses disagree considerably even in the late 1990s, which leads to questions about how in situ winds are weighted in the analyses. It is also possible that analysis procedures involved in producing wind products are very different; therefore the quality of the fields also varies.

\section{d. Solutions in other numerical models}

It should be mentioned that poor NECC simulations also occur in other numerical models. Figure 9 shows the vertically integrated, zonal geostrophic flows (calculated the same way as $M_{\mathrm{ob}}$ for the POA data) from a solution to GFDL's Modular Ocean Model (version 1; MOM1) forced by mean Hellerman and Rosenstein (1983) winds combined with anomalies from the FSU interannual winds using the same $C_{D}$ as here. This solution is, in fact, a twin integration to the one shown in Fig. 3, except without any data assimilation. Similar to our FSU solution, the NECC in MOM1 has distinct relative minima in the central ocean during 1988 and 1990 , although it is never totally interrupted by the westward flow. The MOM1 solution also has much weaker NECC transports (dash-dotted curves in the right panels of Fig. 7) than ours. The reason for these differences is probably due to model differences, but the precise processes causing them are not clear.

\section{Summary}

In this study, two key forcing terms are identified for the Pacific NECC simulation: $(\operatorname{curl} \tau)_{y}$ in the ITCZ that determines the total NECC transport and $\tau^{x}$ in the nearequatorial region that defines the strength of the SEC and the spatial structure of the model NECC.

The solutions reported here suggest that climatological winds have too large $\tau^{x}$ in the near-equatorial region compared to the strength of $(\operatorname{curl} \tau)_{y}$ in the ITCZ region. This error produces a SEC that is too strong, resulting in a discontinuity in the model NECC near the date line. The solutions forced by FSU winds lack year-to-year consistency (right panels of Fig. 6). Their $(\operatorname{curl} \tau)_{y}$ field is too weak compared to the strength of its near-equatorial $\tau^{x}$, which results in unrealistic NECC structures. In contrast, the ECMWF product appears to have a balance between $(\operatorname{curl} \tau)_{y}$ and near-equatorial $\tau^{x}$, which enables it to have a successful simulation of NECC spatial structure from 1989 onward, even though its magnitude remains weaker than observed estimates until 1993.

This study shows that, though ocean models are not perfect, the wind inaccuracy is clearly the main cause for the discrepancy between modeled and observed
NECC. For climatological winds, this inaccuracy may arise from averaging the narrow ITCZ band over time and space, but it more likely results from sparse in situ measurements. For interannual winds, averaging daily winds to form monthly winds weakens the annual-mean NECC a little. We hope more accurate wind products will soon be available, because they are essential for realistic model simulations and they can also help to identify model deficiencies.

Acknowledgments. This study has been supported in part by NOAA/OGP through the PACS program, the NASA Scatterometer Project at JPL, NOAA/NESDIS, and the Frontier Research System for Global Change through its support of the International Pacific Research Center (IPRC). We thank ECMWF, FSU, and the TAO Project Office for providing their wind products. D. E. Harrison provided wind stress fields that his group has constructed from ECMWF winds. The POA data was obtained from the NOAA-CIRES Climate Diagnostics Center, and the MOM1 solution used in Fig. 9 was provided by Yan Xue at NOAA/NCEP. The programming and data-analysis assistance of the Ferret group at NOAA/PMEL, Kevin Kohler, Dai McClurg, Jerry Davison, and Suzanne Dickinson are greatly appreciated. Discussions with Dennis Moore, Mike McPhaden, Yan Xue, Bohua Huang, and Ren-Chieh Lien were helpful.

\section{REFERENCES}

Behringer, D. W., M. Ji, and A. Leetmaa, 1998: An improved coupled model for ENSO prediction and implications for ocean initialization. Part I: The ocean data assimilation system. Mon. Wea. Rev., 126, 1013-1021.

da Silva A., A. C. Young, and S. Levitus, 1994: Atlas of Surface, Marine Data 1994. Vol. 1: Algorithms and Procedures. NOAA Atlas NESDIS 6, U.S. Department of Commerce, 83 pp.

Donguy, J., and G. Meyers, 1996: Mean annual variation of transport of major currents in the tropical Pacific Ocean. Progress in Oceanography, Vol. 43, Pergamon, 1105-1122.

Grima, N., A. Bentamy, K. Katsaros, Y. Quilfen, P. Delecluse, and C. Levy, 1999: Sensitivity of an oceanic general circulation model forced by satellite wind stress fields. J. Geophys. Res., 104, 7967-7989.

Han, W., J. P. McCreary, D. L. T. Anderson, and A. J. Mariano, 1999: Dynamics of the eastward surface jets in the equatorial Indian Ocean. J. Phys. Oceanogr., 29, 2191-2209.

Hellerman, S., and M. Rosenstein, 1983: Normal monthly wind stress over the world ocean with error estimates. J. Phys. Oceanogr., 13, 1093-1104.

Ji, M., and T. M. Smith, 1995: Ocean model response to temperature data assimilation and varying surface wind stress: Intercomparisons and implications for climate forecast. Mon. Wea. Rev., 123, $460-481$.

Johnson, G. C., and M. J. McPhaden, 1999: Interior pycnocline flow from the subtropical to the equatorial Pacific Ocean. J. Phys. Oceanogr., 29, 3073-3089.

Kessler, W. S., 1990: Observations of long Rossby waves in the northern tropical Pacific. J. Geophys. Res., 95, 5183-5217.

—, and B. A. Taft, 1987: Dynamic heights and zonal geostrophic transports in the central Pacific during 1979-84. J. Phys. Oceanogr., 17, 97-122.

Kraus, E. B., and J. S. Turner, 1967: A one-dimensional model of 
the seasonal thermocline: II. The general theory and its consequences. Tellus, 19, 98-106.

Landsteiner, M. C., M. J. McPhaden, and J. Picaut, 1990: On the sensitivity of Sverdrup transport estimates to the specification of wind stress forcing in the tropical Pacific. J. Geophys. Res., 95, 1681-1691.

Large, W. G., and S. Pond, 1981: Open ocean momentum flux measurements in moderate to strong winds. J. Phys. Oceanogr., 11, 324-336.

Levitus, S., 1982: Climatological Atlas of the World Ocean. NOAA Prof. Paper No. 13, U.S. Govt. Printing Office, 173 pp.

Lu, P., J. P. McCreary, and B. A. Klinger, 1998: Meridional circulation cells and the source waters of the Pacific equatorial undercurrent J. Phys. Oceanogr., 28, 62-84.

McCreary, J. P., 1985: Modeling equatorial ocean circulation. Annu. Rev. Fluid Mech., 17, 359-409.

McPhaden, M. J., 1993: TOGA-TAO and the 1991-93 El NiñoSouthern Oscillation event. Oceanography, 6, 36-44.
Philander, S. G. H., and R. C. Pacanowski, 1980: The generation of the equatorial currents. J. Geophys. Res., 85 (C2), 1123-1136.

— W. J. Hurlin, and A. D. Seigel, 1987: Simulation of the seasonal cycle of the tropical Pacific Ocean. J. Phys. Oceanogr., 17, 1986-2002.

Seager, R., and M. B. Blumenthal, 1994: Modeling tropical Pacific sea surface temperature with satellite-derived solar radiative forcing. J. Climate, 7, 1943-1957.

Sverdrup, H. U., 1947: Wind-driven currents in a baroclinic ocean, with application to the equatorial currents of the eastern Pacific. Proc. Natl. Acad. Sci. U.S.A., 33, 318-326.

Taft, B. A., and W. S. Kessler, 1991: Variations of zonal currents in the Central Tropical Pacific during 1970-1987: Sea level and dynamic height measurements. J. Geophys. Res., 96, $12599-$ 12618.

Wyrtki, K., and B. Kilonsky, 1984: Mean water and current structure during the Hawaii-to-Tahiti Shuttle Experiment. J. Phys. Oceanogr., 14, 242-254. 